Research Article

\title{
Hydrodynamics of Compound Droplet Flowing in the Curved Minichannel
}

\author{
Meimei Sun, ${ }^{1}$ Miao Zhao, ${ }^{1}$ and Wei Gao $\mathbb{D}^{1,2}$ \\ ${ }^{1}$ Key Laboratory of Energy Thermal Conversion and Control of Ministry of Education, School of Energy and Environment, \\ Southeast University, Nanjing 210096, China \\ ${ }^{2}$ School of Engineering and Applied Science, Harvard University, Cambridge 02138, USA \\ Correspondence should be addressed to Wei Gao; weigao@seu.edu.cn
}

Received 3 August 2019; Revised 24 September 2019; Accepted 1 October 2019; Published 15 October 2019

Guest Editor: Xiang-Dong Liu

Copyright (C) 2019 Meimei Sun et al. This is an open access article distributed under the Creative Commons Attribution License, which permits unrestricted use, distribution, and reproduction in any medium, provided the original work is properly cited.

Based on the volume of fluid (VOF) method, a theoretical model of compound droplet deformation in curved minichannel is developed. The effects of curved angle, continuous phase, radius ratio between the inner and integral droplets, and viscosity of the middle phase are examined to reveal the underlying mechanism of compound droplet deformation. The results indicate that the deformation process of the compound droplets in the curved minichannel can be divided into three stages, namely, the initial stage, the turning stage, and the adjustment stage. Both large curved angle and high capillary number of the continuous phase result in the large shear force and high eccentricity of the compound droplet. However, as the radius ratio increases, the influence of the inner droplet on the deformation of the compound droplet transits from enhancing to suppressing.

\section{Introduction}

Core fluid encapsulated in the shell fluid, referred as compound droplet, is useful in the storage, transportation, and controlled release of the functional materials, which has a great potential in microreactor $[1,2]$, drug delivery $[3,4]$, thermal management [5-7], and fusion engineering target [8-10]. Usually, the channel is not designed straightly, so the compound droplet may deform sharply and even break up in the shear flow caused by the curved channel. Therefore, knowing the hydrodynamics of the compound droplets is crucial to precisely control the flow phenomena of the compound droplet paving the way for related applications $[11,12]$.

Several attempts have been applied to research the multiphase flow phenomena in the curved channel $[13,14]$. Che et al. $[15,16]$ investigate the flow pattern of a confined droplet moving in curved microchannels based on the analytical method. The flow resistance coefficient decreases due to the increasing droplet size and the microchannel curvature. Using the inertial focusing technique, Wewala et al. [17] simulate the cell separation in ascending and descending curvilinear microchannels. Based on the volume of fluid (VOF) method, the hydrodynamics of droplets moving along the serpentine microchannel in the mixing process is studied [18]. However, the available studies are on the hydrodynamics of the singlephase droplet [19]. The compound droplet undergoes a quite different deformation process from the single-phase droplet under the shear force [20]. Chen et al. numerically studied the morphology evolution of the compound droplet under shear [21]. Three kinds of mechanisms are applied to describe the four types of breakup modes. Compared with the single-phase droplet, the compound droplet can exhibit enhancing or suppressing steady deformation, depending on the radius ratio [22]. Nevertheless, the deformation of the compound droplet in a curved channel is still less understood, especially the effect of the flow field on the concentricity and sphericity of the compound droplet.

To provide a guideline for the design of the curved minichannel and the manipulation of the flow field in the curved minichannel, it is extremely important to develop a quantitative analysis that considers the effect of the confinement and the parameters of the liquid. Therefore, based on the VOF method, a theoretical model of the deformation 
behaviors of the compound droplets in the curved minichannel is developed to investigate the hydrodynamics of the compound droplets in the curved minichannel. The effects of curved angle, continuous phase, radius ratio, and viscosity of the middle phase are analyzed to reveal the deformation mechanism of the compound droplets in the curved minichannel. The current simulation provides a deep understanding of the hydrodynamic behaviors of the compound droplet in the curved minichannel.

\section{Mathematical Model}

To investigate the hydrodynamics of the compound droplet in the curved minichannel, a two-dimensional theoretical model of compound droplets flowing in a curved minichannel is developed. As shown in Figure 1(a), the inner diameter of the curved minichannel is $D=0.5 \mathrm{~mm}$. The compound droplets flow continuously into the curved minichannel from the left inlet and then through the first straight section with length $L=6 \mathrm{D}$. Afterward, the compound droplets turn left at the corner with the turning angle $\theta$ and inner curvature radius $R$ and finally flow through the second straight section with the length $H=4 D$. Before the inlet, the compound droplets including middle phase (density $\rho_{\mathrm{m}}$ and viscosity $\mu_{\mathrm{m}}$ ) and dispersed phase (density $\rho_{\mathrm{d}}$ and viscosity $\mu_{\mathrm{d}}$ ) are initially set in a rectangular shape and repeat periodically in minichannels, shown in Figure 1(b). The shape of the compound droplets will transform while the droplet is flowing with the continuous phase (density $\rho_{\mathrm{c}}$ and viscosity $\mu_{\mathrm{c}}$ ).

2.1. Governing Equation. In this study, the VOF method [23-25] is applied to simulate the deformation of the compound droplet in the curved minichannel. The incompressible fluids of the dispersed phase, middle phase, and continuous phase are considered to be Newtonian and immiscible with each other. The volume fraction $\alpha$ in one cell follows the below equation:

$$
\alpha_{\mathrm{c}}+\alpha_{\mathrm{m}}+\alpha_{\mathrm{d}}=1,
$$

where $\alpha_{\mathrm{c}}, \alpha_{\mathrm{m}}$, and $\alpha_{\mathrm{d}}$ are the volume fractions of the continuous phase, middle phase, and dispersed phase, respectively. The density $\rho$ and viscosity $\mu$ in one cell are calculated as follows:

$$
\begin{aligned}
& \rho=\alpha_{\mathrm{c}} \rho_{\mathrm{c}}+\alpha_{\mathrm{m}} \rho_{\mathrm{m}}+\alpha_{\mathrm{d}} \rho_{\mathrm{d}}, \\
& \mu=\alpha_{\mathrm{c}} \mu_{\mathrm{c}}+\alpha_{\mathrm{m}} \mu_{\mathrm{m}}+\alpha_{\mathrm{d}} \mu_{\mathrm{d}} .
\end{aligned}
$$

The densities of the three phases are all $1000 \mathrm{~kg} / \mathrm{m}^{3}$, so the gravity force is neglected. Moreover, the viscosities of the three phases are $\mu_{\mathrm{c}}=\mu_{\mathrm{d}}=0.005 \mathrm{~Pa} \cdot \mathrm{s}, \mu_{\mathrm{m}}=0.05 \mathrm{~Pa} \cdot \mathrm{s}$, for the typical condition. The densities and viscosities of each phase are assumed to be constant through the process. The continuity equation is as follows:

$$
\nabla \cdot U=0
$$

where $U$ is the velocity of the fluid. The transport equations are as follows:

$$
\begin{aligned}
& \frac{\partial \alpha_{\mathrm{c}}}{\partial t}+\nabla \cdot\left(U \cdot \alpha_{\mathrm{c}}\right)=0, \\
& \frac{\partial \alpha_{\mathrm{m}}}{\partial t}+\nabla \cdot\left(U \cdot \alpha_{\mathrm{m}}\right)=0, \\
& \frac{\partial \alpha_{\mathrm{d}}}{\partial t}+\nabla \cdot\left(U \cdot \alpha_{\mathrm{d}}\right)=0 .
\end{aligned}
$$

And the momentum equation is given by

$$
\frac{\partial U}{\partial t}+\nabla \cdot(U U)=-\frac{\nabla p}{\rho}+\nabla \cdot \frac{\mu}{\rho}\left[\nabla U+\nabla U^{T}\right]+f,
$$

where $p$ is the pressure and $f$ is the source term calculated via the continuum surface force (CSF) approach [26-28]. And the interfacial tension coefficients of the inner interface $\sigma_{\mathrm{i}}$ and the outer interface $\sigma_{\mathrm{o}}$ are $0.001 \mathrm{~N} / \mathrm{m}$.

2.2. Numerical Solutions. The finite volume-based commercial software Fluent 6.3 is used to solve the governing equations. The computational domains of the curved minichannel presented in Figure 1 are discrete $d$ by structured quadrilateral meshes. The finite volume method is used to solve the governing equations in this study. The discretization of the momentum equation is calculated by the second-order upwind scheme. Generally, the average Reynold number for the flows in the curved minichannel is less than 10 , so that the flow can be treated as the laminar flow. The pressure and velocity coupling is achieved by using the Semi-Implicit Method for Pressure-Linked Equations (SIMPLE) algorithm. The interface is reconstructed following the second-order piecewise linear interface construction (PLIC) [29] method.

2.3. Grid Independence Test. To verify the grid independence, several different sizes of mesh are used. Figure 2 shows the compound droplet flowing in the curved minichannel at different mesh resolutions. As shown in the figure, there is a dispersion of inner droplet motion for cell number of 23604 and 73360 . Nevertheless, the difference in simulation results between 73360 and 106970 cells is minor. Since the increase in the cell number induces greater computational cost, the cell number of 250399 is adopted for the current simulation.

2.4. Case Validation. To validate the theoretical model, the numerical simulation is compared with the experimental results. Figure 3 shows the schematic of the validation experiment setup, including syringe bumps, curved minichannel, high-speed camera, and computer. The water solutions with 5\% wt. polyvinyl alcohol are used as inner phase and continuous phase. The benzene and dichloroethane solution with $7 \% \mathrm{wt}$. polystyrene is used as the middle phase. The high-speed camera (Photron, FASTCAM SA4) is used to capture the motion of the compound droplet. The syringe pumps (Longer, LSP01-1BH) are used to generate compound droplets with a microfluidic chip. The flow rates of the inner phase, middle phase, and continuous phase 


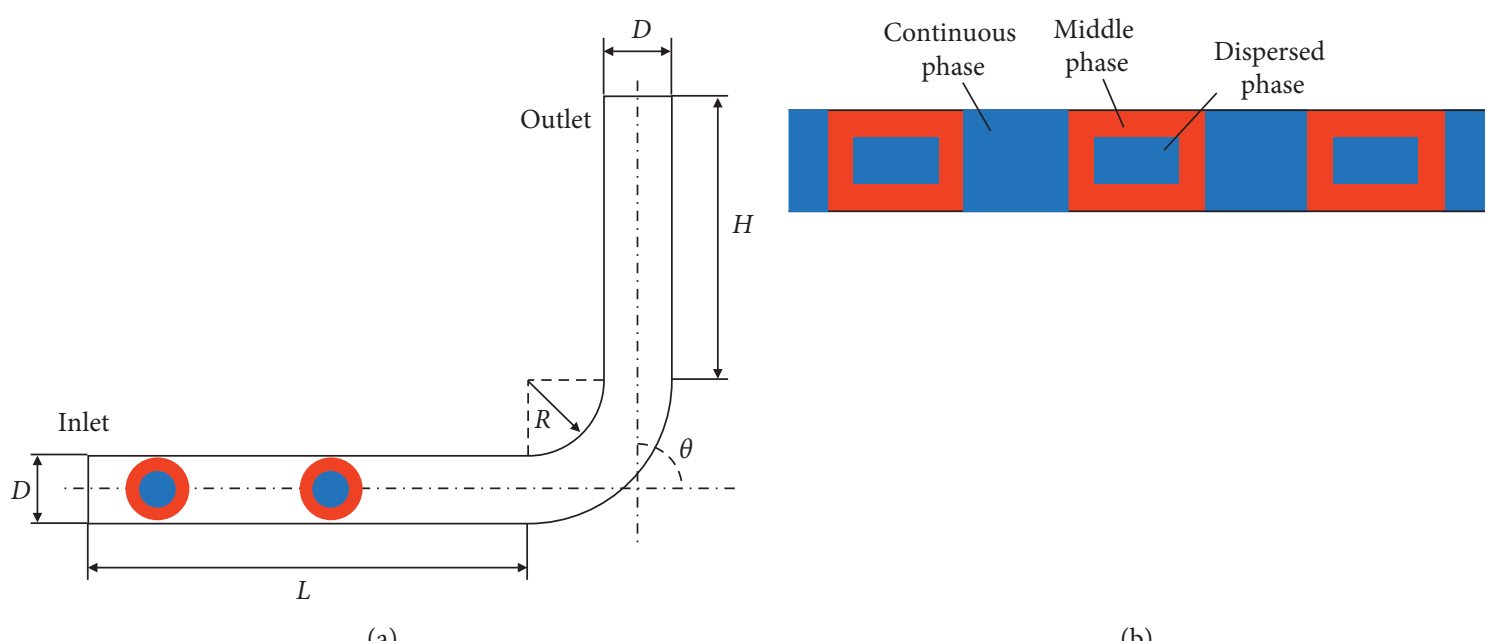

(a)

(b)

Figure 1: Schematics and computational domain of the mathematical model: (a) compound droplet deformation in the curved minichannel; (b) compound droplet formation.

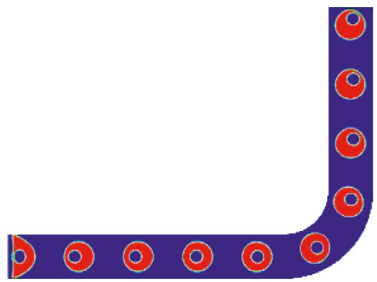

(a)

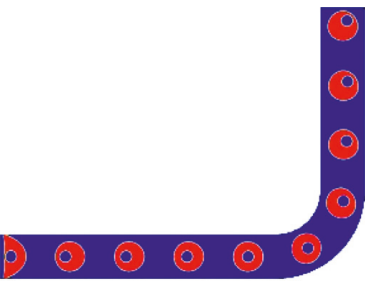

(b)

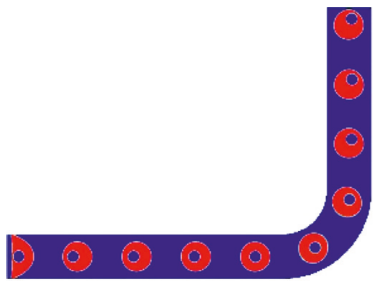

(c)

FiguRe 2: Grid independence test of different cell numbers $n_{\mathrm{c}}$ : (a) $n_{\mathrm{c}}=23604$; (b) $n_{\mathrm{c}}=73360$; (c) $n_{\mathrm{c}}=106970$.

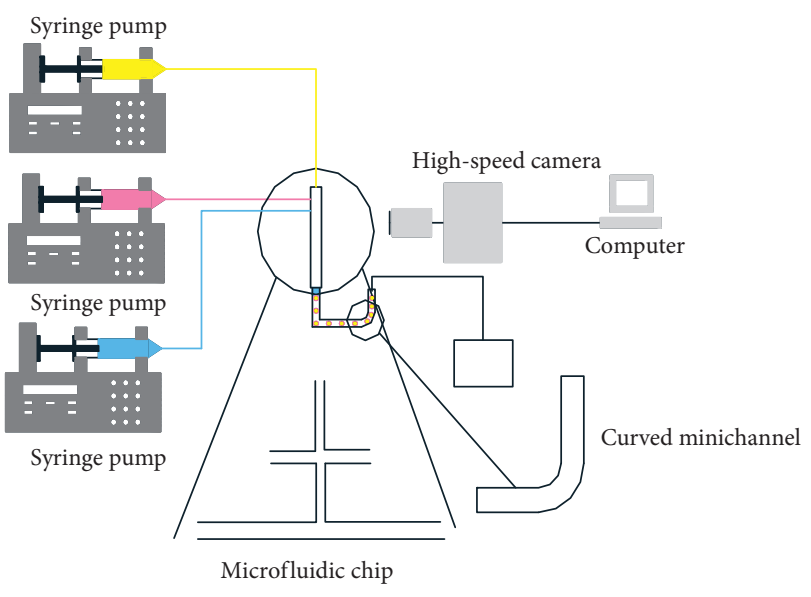

FIgURE 3: Schematic of the validation experiment setup.

are $5 \mathrm{ml} / \mathrm{h}, 5 \mathrm{ml} / \mathrm{h}$, and $15 \mathrm{ml} / \mathrm{h}$, respectively. Figure 4 compares the numerical simulation with the experimental results with different curved angles. The good agreements validate that the theoretical model is capable of predicting the hydrodynamic behavior of the compound droplet in the curved minichannel.

\section{Results and Discussion}

Based on the above model, the deformation behaviors of the compound droplets in the curved minichannel are predicted. The effects of curved angle, continuous phase, radius ratio, and viscosity of the middle phase are analyzed to reveal the deformation mechanism of the compound droplets in the curved minichannel.

3.1. The Deformation Behaviors of the Compound Droplet in the Curved Minichannel. Figure 5 illustrates the deformation process of the compound droplets in the curved minichannel, which can be divided into three stages, i.e., the initial stage, the turning stage, and the adjustment stage. During the initial stage, the compound droplet moves forward in the first straight section of the curved minichannel, driven by the syringe pump, shown in Figure 5(a). Figure 5(b) shows that the velocity at the center of the minichannel is the largest for the developed flow. Therefore, the inner droplet gradually moves towards the front of the compound droplet. During the turning stage, due to the centrifugal force at the curve, the velocity of the flow decreases and the pressure increases towards the center of the curve, resulting in the inner droplet moving radial direction. In the adjustment stage, the compound droplets move 

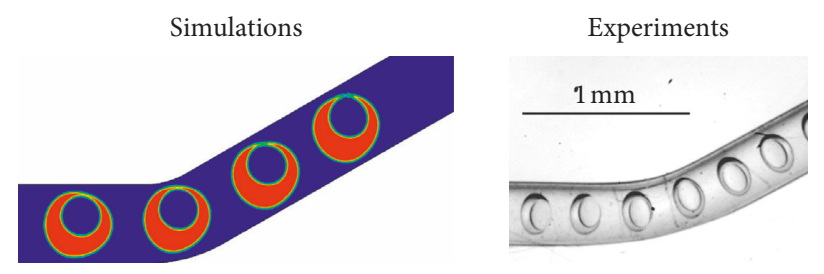

(a)

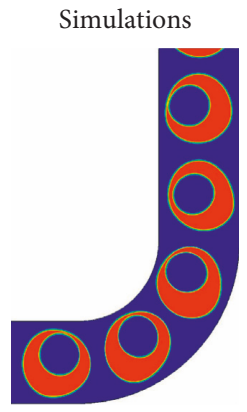

Simulations

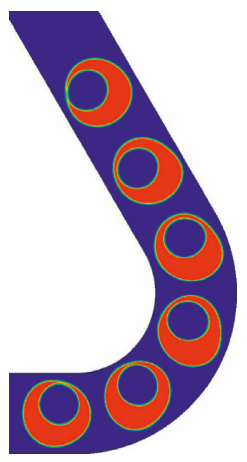

Simulations

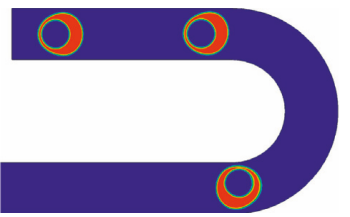

Experiments

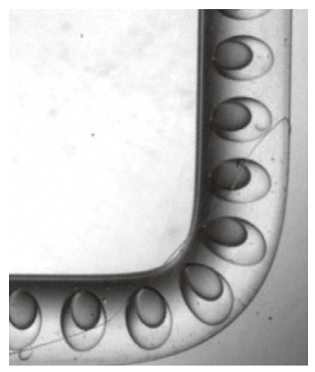

(b)

Experiments

(c)
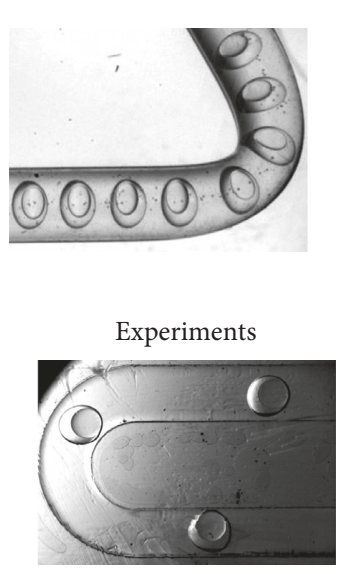

(d)

Figure 4: Comparison of the numerical simulation and the experimental results of compound droplet deformation in the curved minichannel: (a) $\theta=30^{\circ}$; (b) $\theta=90^{\circ}$; (c) $\theta=120^{\circ}$; (d) $\theta=180^{\circ}$.

forward in the second straight section of the curved minichannel. The compound droplet adjusts its shape to fit the developed channel flow. As shown in Figure 5(c), the increasing pressure gradient induced by the droplet deformation may lead to the breakup of the compound droplet.

3.2. Effect of the Curved Angle. There are diversities of the microfluidic device structures, especially the curved channels with different angles. Therefore, it is urgent to study the effect of the curved angle on the droplet deformation. Figure 6 shows the interface shape, pressure distribution, and velocity distribution of the curved minichannel with different curved angles. As the curved angle increases, there is more likely the breakup of the compound droplet. It mainly attributes to the increasing length of the curve, even though the radii of curvature and the centrifugal forces are the same. With the longer time at the turning, the pressure difference between inside and outside the compound droplet is larger, inducing a greater droplet deformation. As the inner droplet moves along the radial direction, there is less middle phase fluid near the wall between the dispersed phase and the continuous phase. Therefore, the eccentricity of the compound droplet is higher, and the breakup is easier to happen. According to the above simulation, large curved angle should be avoided in real applications. 


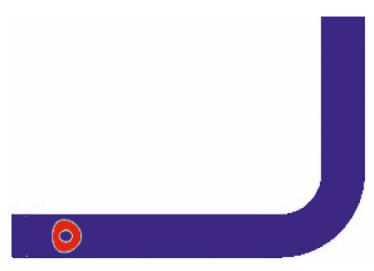

$t=5 \mathrm{~s}$

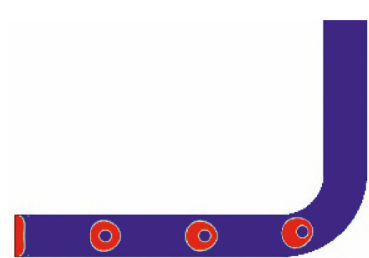

$t=25 \mathrm{~s}$

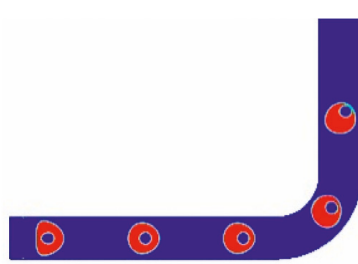

$t=40 \mathrm{~s}$

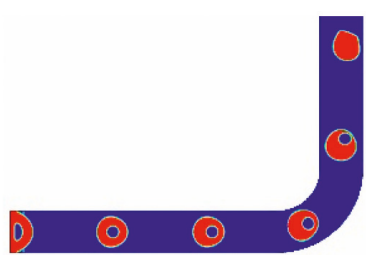

$t=45 \mathrm{~s}$

(a)
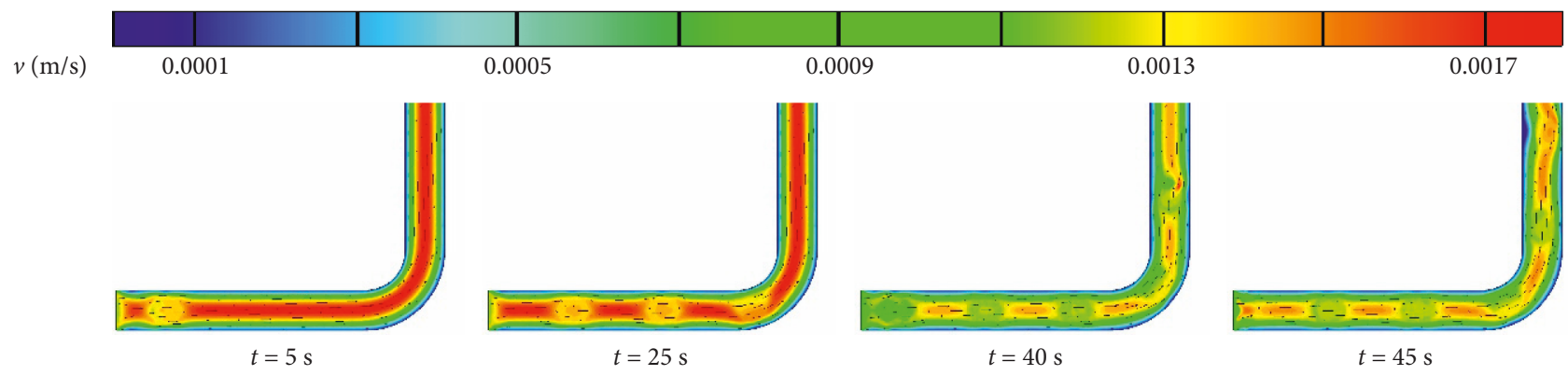

(b)

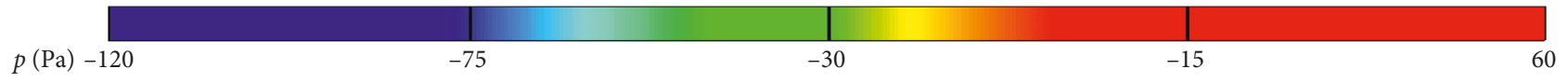

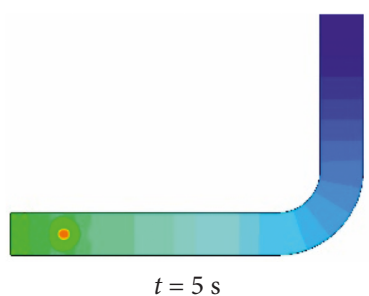

$t=5 \mathrm{~s}$

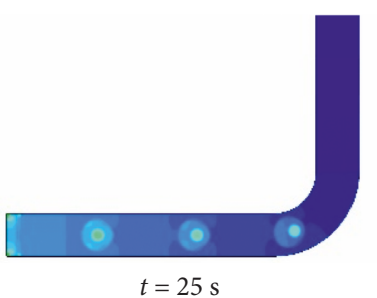

(c)
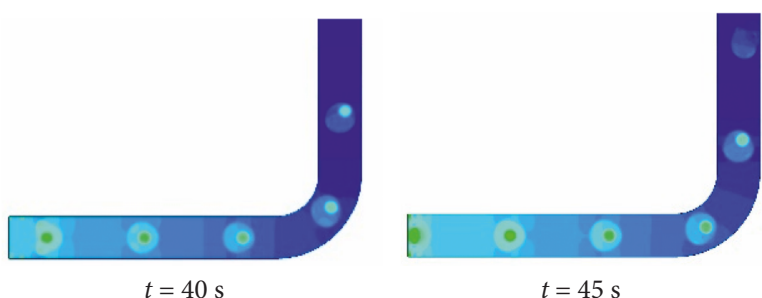

Figure 5: Time revolution of compound droplet deformation in the curved minichannel: (a) interface shape; (b) pressure distribution; (c) velocity distribution.

3.3. Effect of the Continuous Phase. The external fluid has a significant impact on the hydrodynamic behavior of the compound droplet. Hence, we introduce capillary number of the continuous phase Ca to generally analyze the effect of the continuous phase on the hydrodynamic behavior of the compound droplet:

$$
\mathrm{Ca}=\frac{\mu_{\mathrm{c}} u_{\mathrm{c}}}{\sigma_{\mathrm{o}}}
$$

where $\mu_{c}$ is the dynamic viscosity of the continuous phase and $u_{\mathrm{c}}$ is the average inlet velocity in the continuous phase.

As shown in Figure 7, with the increase of capillary number, the enhanced viscous effect of the continuous phase makes the compound droplet undergo a greater shear force from the continuous phase, resulting in the deformation of the compound droplet. The enhanced viscous also induces larger velocity gradient, so that the inner droplet moves far away from the center of the compound droplet, shown in Figure 8. Moreover, as shown in Figure 9, due to the weakened interfacial tension effect, the pressure in the middle phase is smaller, and the deformation of the compound droplet is hard to resist, especially parallel the direction of the minichannel. The presence of the inner droplet may lead to an oscillating deformation of the integral droplet. Therefore, with a relatively large capillary number, the concentricity of the compound droplet is larger, and the thickness of the middle phase near the wall is smaller, eventually leading to the breakup of the compound droplet.

3.4. Effect of Radius Ratio between Inner and Integral Droplets. The radius ratio between inner and integral droplets $k$ is a critical factor to the deformation of the compound droplet, as the deformation of the integral droplet is affected by the deformation of the inner droplet. Figure 10 compares the deformation of the compound droplet with different radius ratios. At a low radius ratio, the motion and deformation of the inner droplet promote the deformation of the integral droplet. As the radius ratio grows, the high-pressure region in the inner droplet becomes closer to the outer interface. Consequently, the pressure gradient near the outer interface becomes larger, leading to a smaller curvature of the interface. Especially at a high radius ratio, the deformation of the integral droplet is suppressed by the inner droplet. 
Interface shape

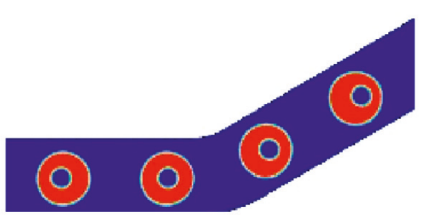

Interface shape

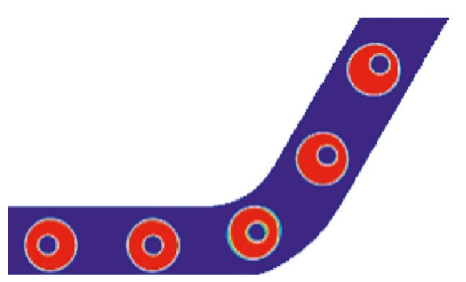

Interface shape

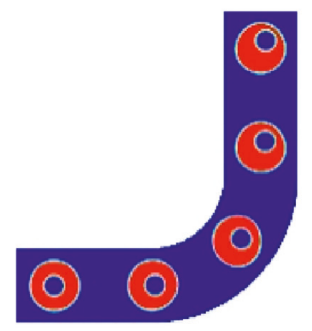

Interface shape

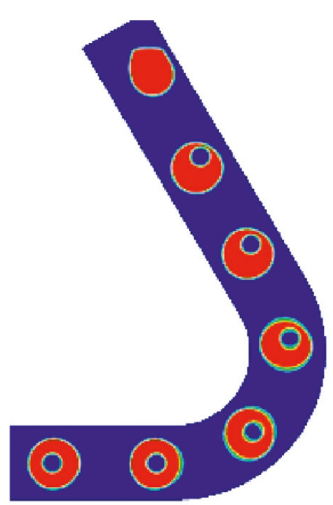

Pressure distribution
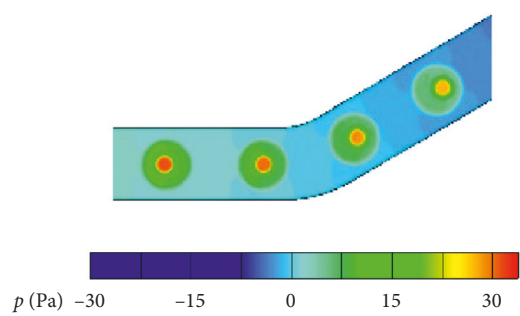

(a)

Pressure distribution

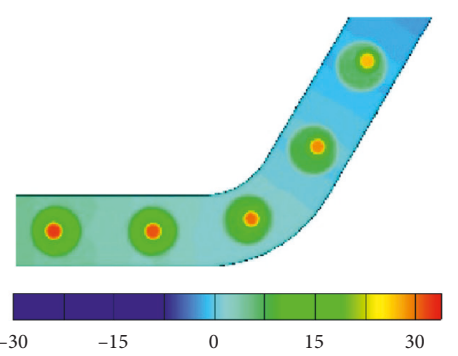

(b)

Pressure distribution

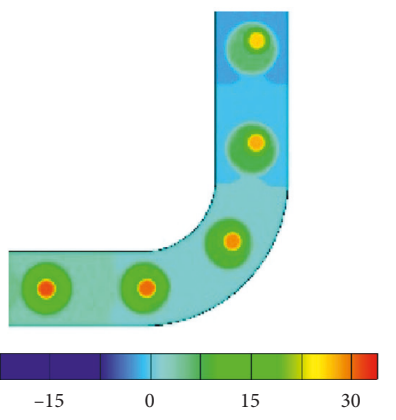

(c)

Pressure distribution

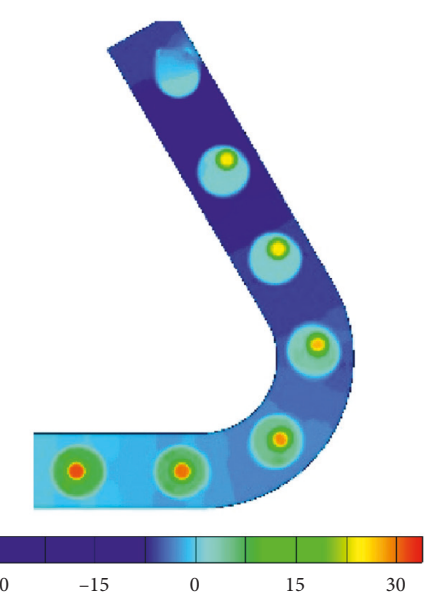

(d)
Velocity distribution
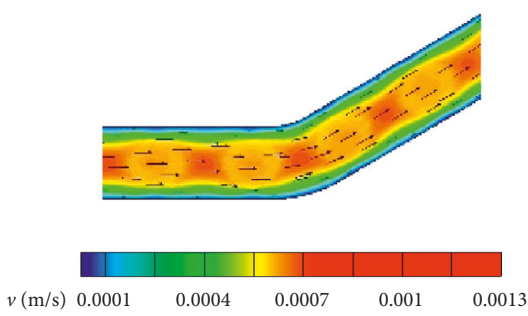

Velocity distribution
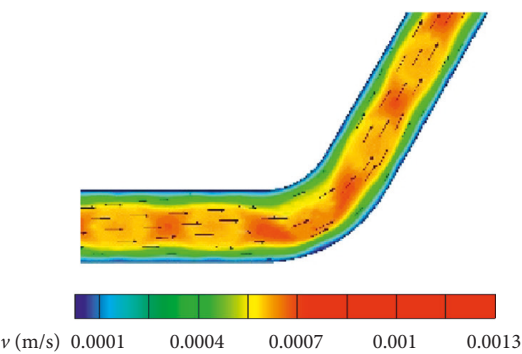

Velocity distribution
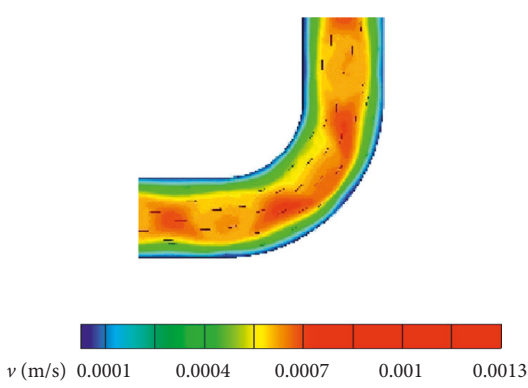

Velocity distribution

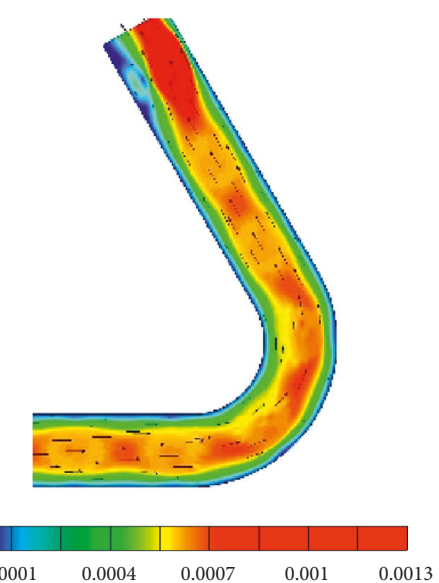

FIgURE 6: Continued. 

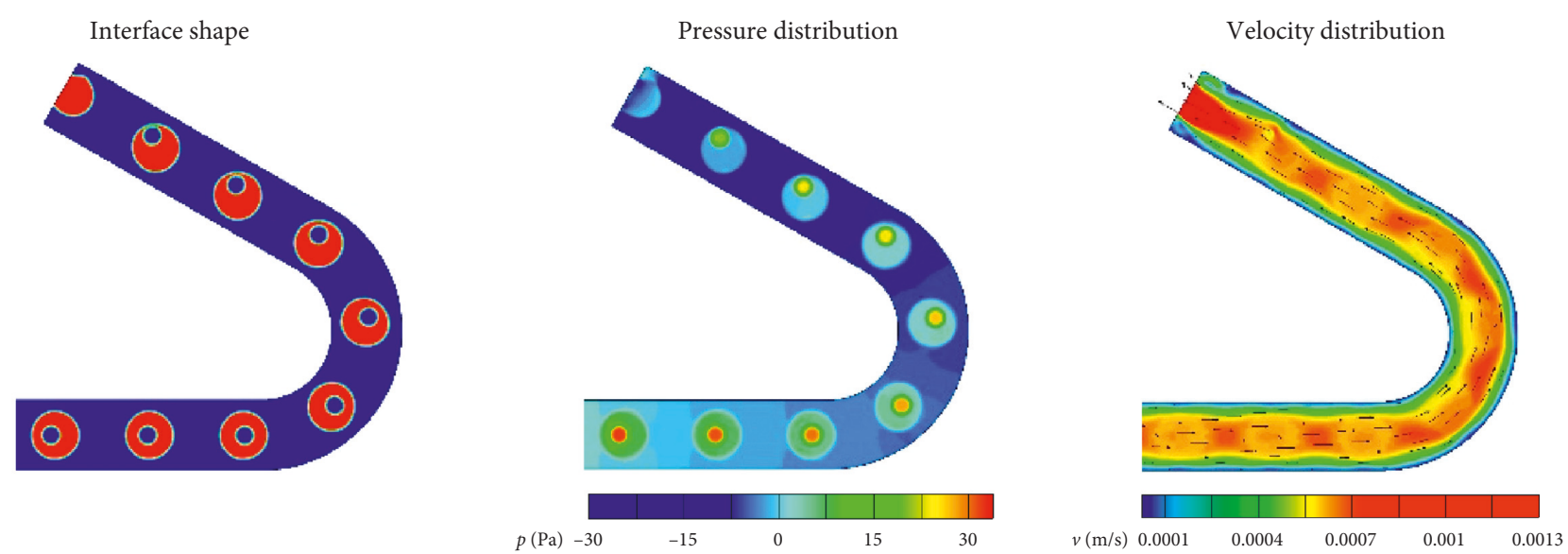

Interface shape
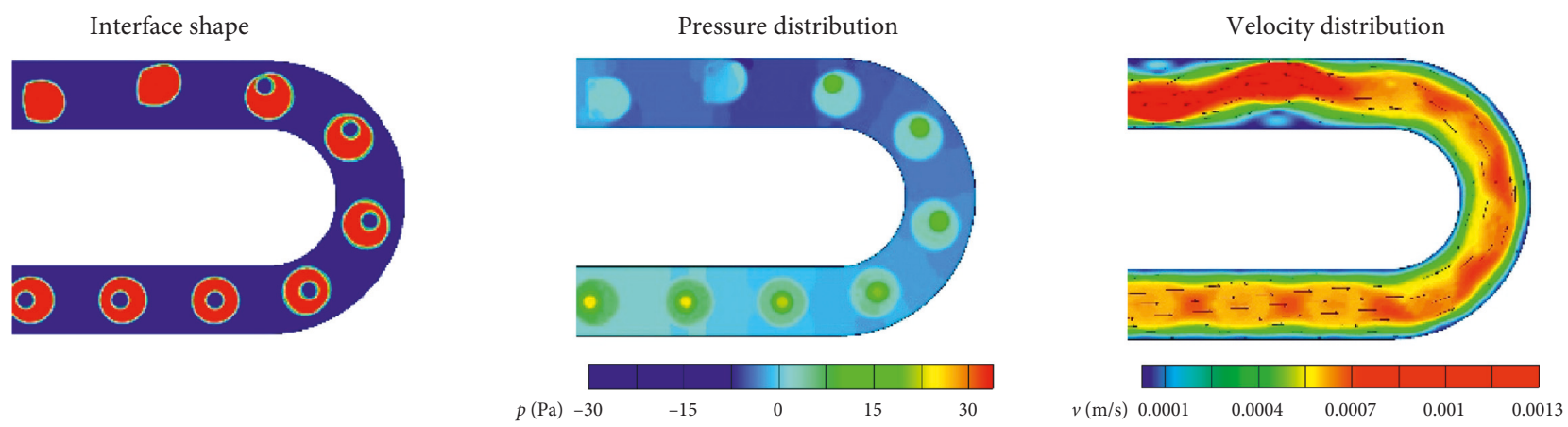

(f)

Figure 6: Effect of curved angle on the compound droplet deformation: (a) $\theta=30^{\circ}$; (b) $\theta=60^{\circ}$; (c) $\theta=90^{\circ}$; (d) $\theta=120^{\circ}$; (e) $\theta=150^{\circ}$; (f) $\theta=180^{\circ}$.

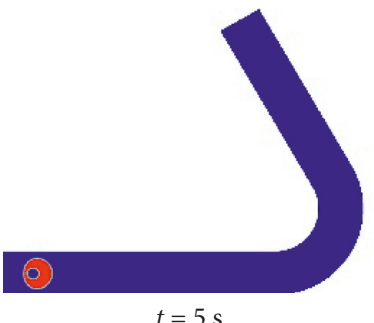

$t=5 \mathrm{~s}$

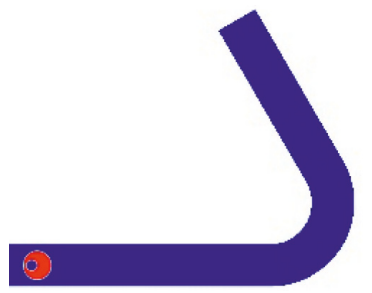

$t=5 \mathrm{~s}$

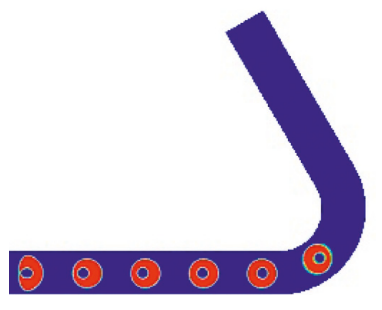

$t=28 \mathrm{~s}$

(a)

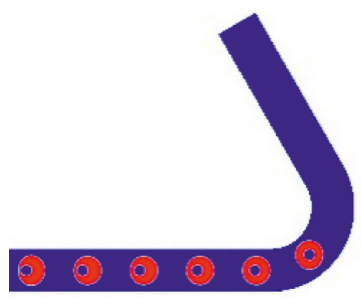

$t=28 \mathrm{~s}$

(b)
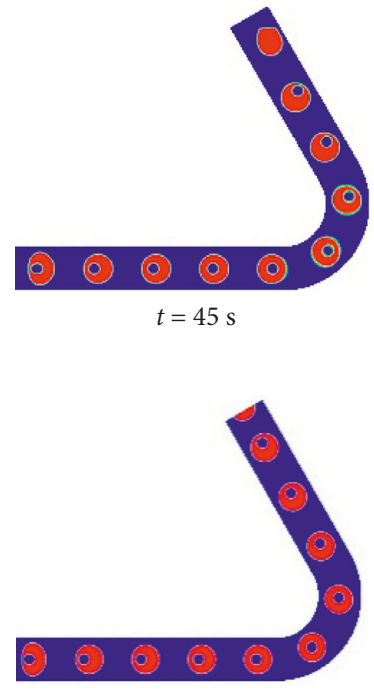

$t=45 \mathrm{~s}$

FIGURE 7: Effect of capillary number of continuous phase on the interface shape during compound droplet deformation: (a) Ca $=0.05$; (b) $\mathrm{Ca}=0.025$.

3.5. Effect of the Viscosity of the Middle Phase. Figure 11 shows the effect of viscosity of the middle phase on the compound droplet deformation. As the viscosity of the middle phase increases, the increasing inertial effect suppresses the deformation of the compound droplet. Moreover, the motion of the inner droplet undergoes more 


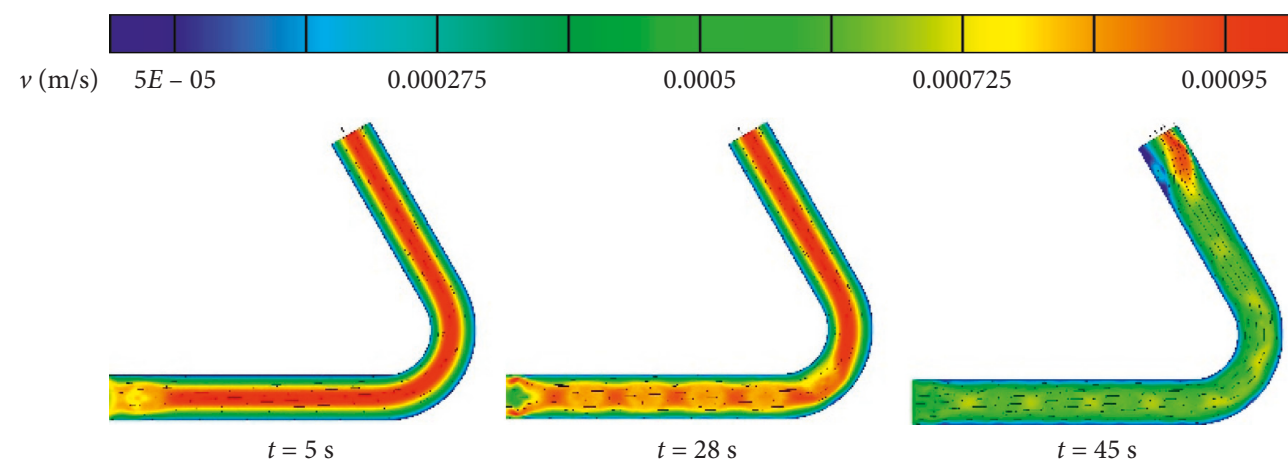

(a)

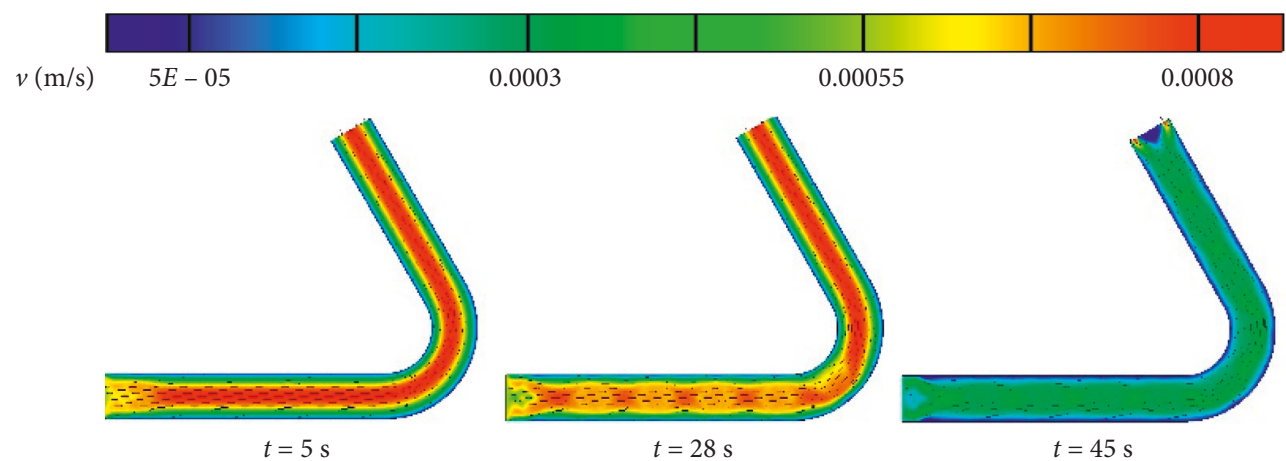

(b)

Figure 8: Effect of capillary number on the velocity distribution during compound droplet deformation: $(\mathrm{a}) \mathrm{Ca}=0.05$; $(\mathrm{b}) \mathrm{Ca}=0.025$.

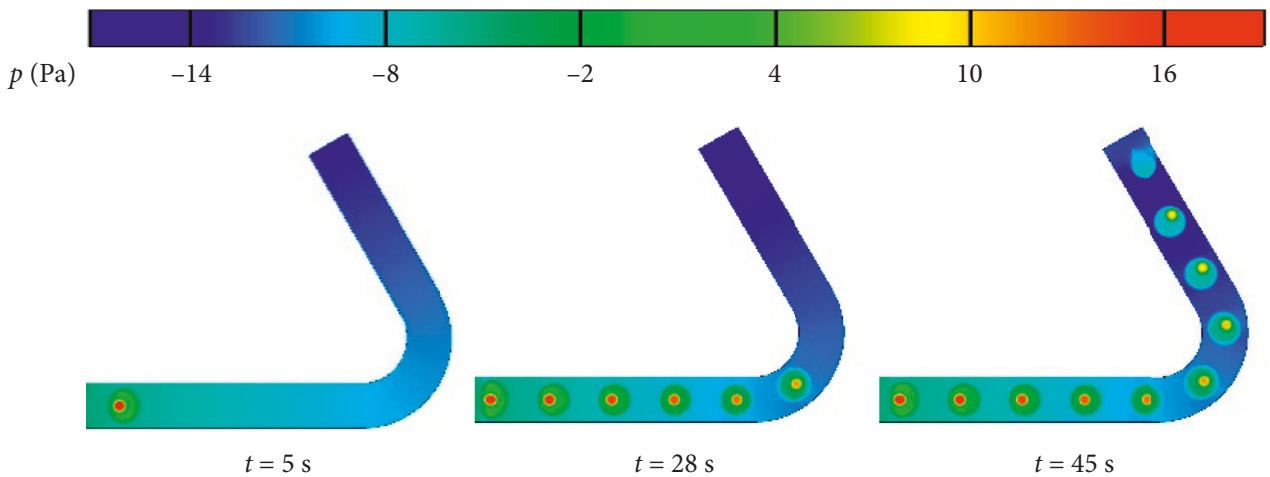

(a)

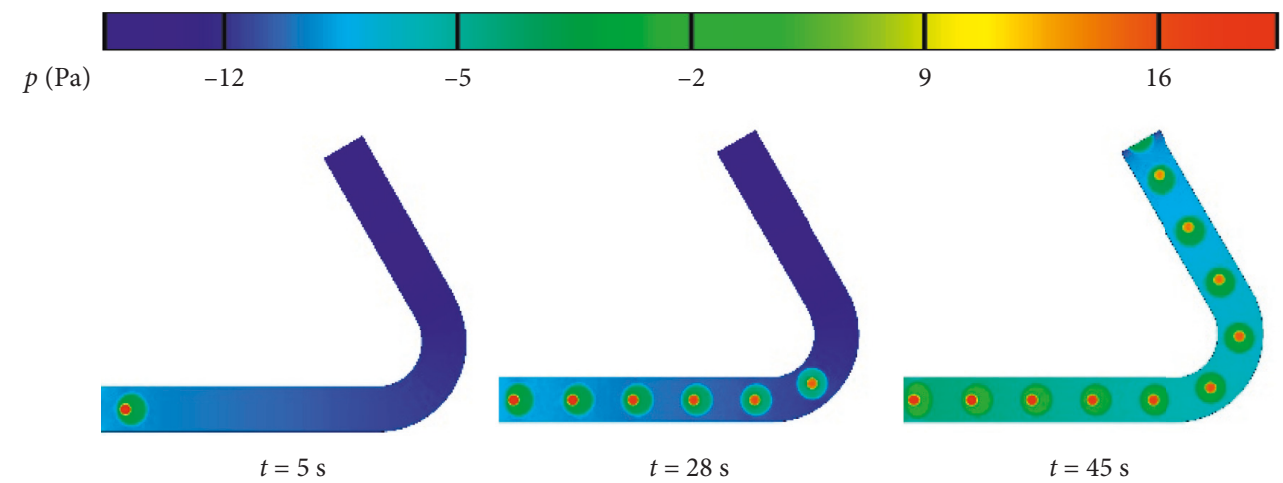

(b)

FiguRE 9: Effect of capillary number on the pressure distribution during compound droplet deformation: $(\mathrm{a}) \mathrm{Ca}=0.05$; (b) $\mathrm{Ca}=0.025$. 


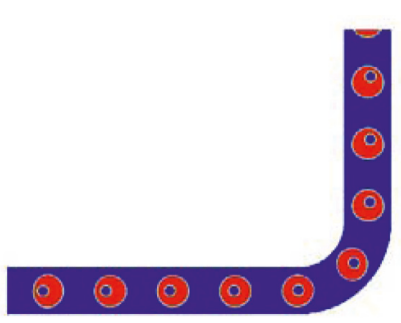

$k=0.4$

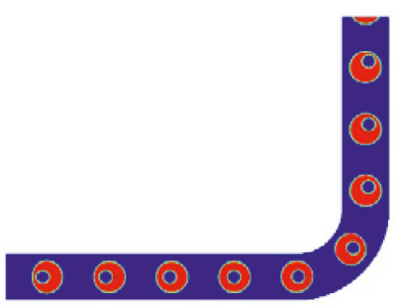

$k=0.5$

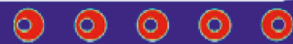

$k=0.6$

(a)
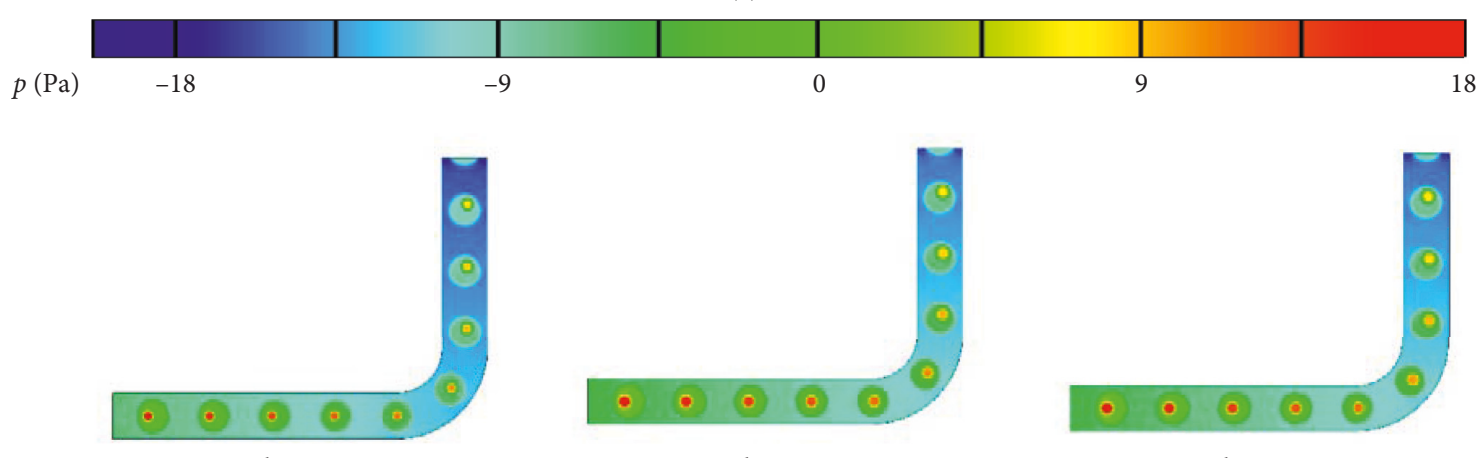

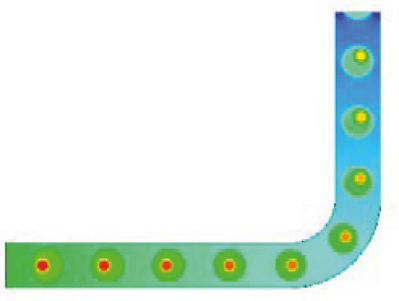

$k=0.5$

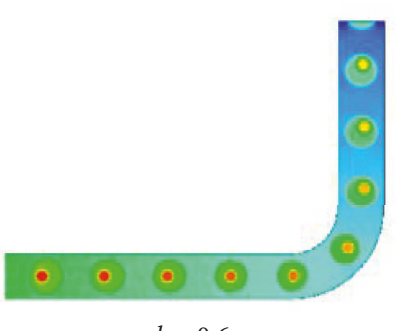

$k=0.6$

(b)

Figure 10: Effect of radius ratio on the compound droplet deformation: (a) interface shape; (b) pressure distribution.

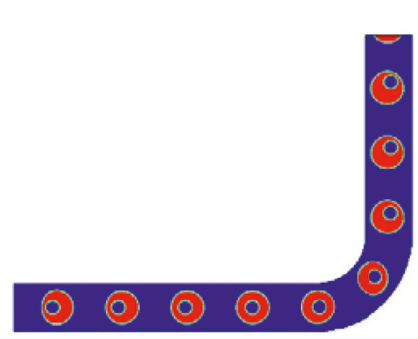

$\mu_{\mathrm{m}}=0.5 \mathrm{~Pa} \cdot \mathrm{s}$

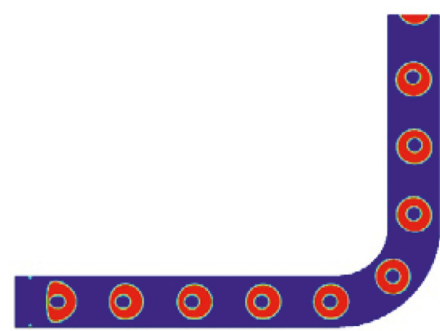

$\mu_{\mathrm{m}}=1 \mathrm{~Pa} \cdot \mathrm{s}$
(2) (c) (c) (2) (0)

$\mu_{\mathrm{m}}=1.5 \mathrm{~Pa} \cdot \mathrm{s}$

(a)
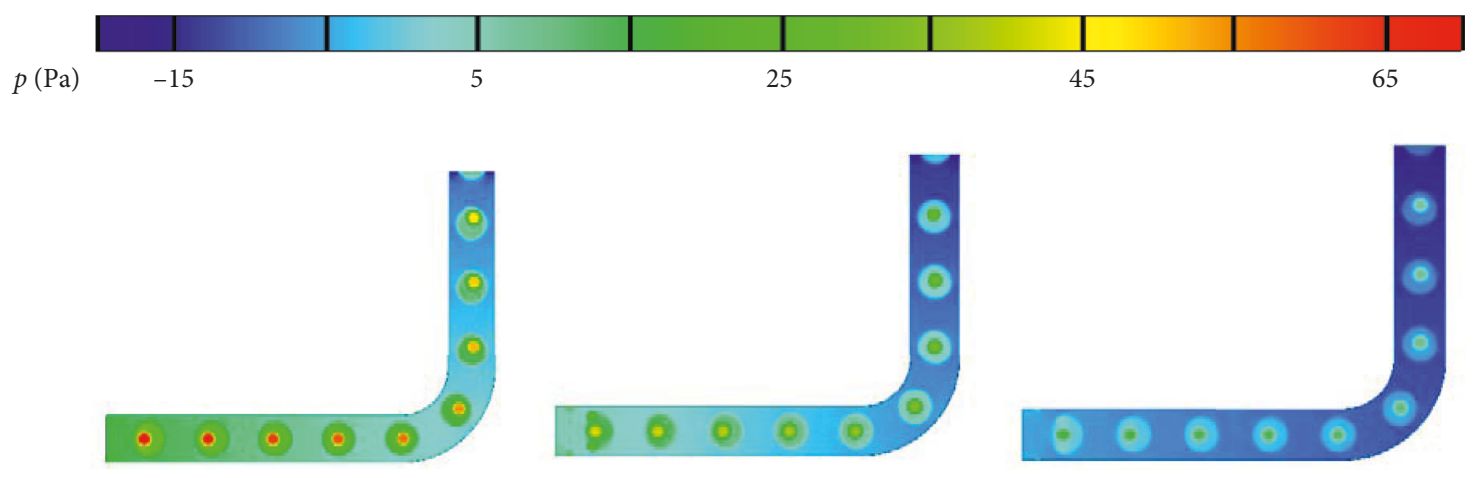

$\mu_{\mathrm{m}}=0.5 \mathrm{~Pa} \cdot \mathrm{s}$

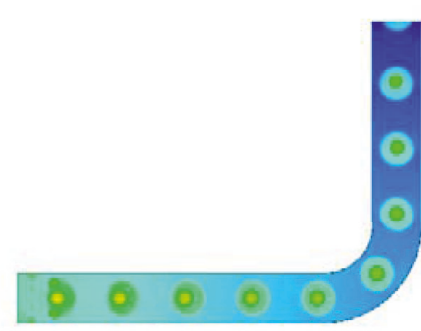

$\mu_{\mathrm{m}}=1 \mathrm{~Pa} \cdot \mathrm{s}$

(b)

FIGURE 11: Effect of the viscosity of the middle phase on the compound droplet deformation: (a) interface shape; (b) pressure distribution. 
resistance, resulting in the low concentricity of the compound droplet. As shown in Figure 11(b), the pressure difference across the outer interface is larger with high viscosity of the middle phase, indicating that the deformation of the compound droplet is larger.

\section{Conclusions}

Based on the VOF method, a theoretical model of the deformation behaviors of the compound droplets in the curved minichannel is developed to investigate the hydrodynamics of the compound droplets in the curved minichannel. The effects of curved angle, continuous phase, radius ratio, and viscosity of the middle phase are analyzed to reveal the deformation mechanism of the compound droplets in the curved minichannel. The results indicate that

(1) The motion of the compound droplets in the curved minichannel can be divided into three stages, i.e., the initial stage, the turning stage, and the adjustment stage.

(2) As the curved angle increases, the eccentricity of the compound droplet is higher and the breakup is easier to occur, due to the higher shear force.

(3) With a relatively large capillary number, the compound droplet exhibits greater deformation due to the increasing shear force from the continuous phase, eventually leading to the breakup of the compound droplet.

(4) At a low radius ratio, the deformation of the integral droplet is promoted by the motion and deformation of the inner droplet. However, at a high radius ratio, the deformation of the integral droplet is suppressed by the inner droplet.

This simulation not only provides a deep understanding of hydrodynamic behaviors of the compound droplet flowing in the curved minichannels but also contributes to precisely controlling the concentricity and sphericity of the compound droplet, which is of significance for the application of the microspheres. Three-dimensional simulation with a more complex channel structure may be considered in the future research work.

\section{Nomenclature}

Ca: Capillary number

$k$ : Radius ratio between the inner and integral droplets

$n_{c}$ : Cell numbers

$p: \quad$ Pressure $(\mathrm{Pa})$

$t$ : $\quad$ Time (s)

$U$ : Velocity of the fluid $(\mathrm{m} / \mathrm{s})$

Greek symbols

$\theta$ : Curved angle $\left(^{\circ}\right)$

$\alpha$ : Volume fraction

$\mu$ : Dynamic viscosity $(\mathrm{Pa} \cdot \mathrm{s})$

$\rho:$ Density $\left(\mathrm{kg} \mathrm{m}^{-3}\right)$

$\sigma$ : Surface tension $(\mathrm{N} / \mathrm{m})$
Subscripts
c: Continuous phase
m: Middle phase
d: Dispersed phase
i: Inner interface
o: Outer interface.

\section{Data Availability}

The data used to support the findings of this study are included within the article.

\section{Conflicts of Interest}

The authors declare that there are no conflicts of interest regarding the publication of this paper.

\section{Acknowledgments}

This work was supported by the National Natural Science Foundation of China (no. 51776037).

\section{References}

[1] C. Zhang, F. Yu, X. Li, and Y. Chen, "Gravity-capillary evaporation regimes in microgrooves," AIChE Journal, vol. 65 , no. 3, pp. 1119-1125, 2019.

[2] H. Song, D. L. Chen, and R. F. Ismagilov, "Reactions in droplets in microfluidic channels," Angewandte Chemie International Edition, vol. 45, no. 44, pp. 7336-7356, 2006.

[3] B. Hadwen, G. Broder, D. Morganti et al., "Programmable large area digital microfluidic array with integrated droplet sensing for bioassays," Lab on a Chip, vol. 12, no. 18, pp. 3305-3313, 2012.

[4] Y. Gao, C. U. Chan, Q. Gu et al., "Controlled nanoparticle release from stable magnetic microbubble oscillations," NPG Asia Materials, vol. 8, no. 4, p. e260, 2016.

[5] J. Wang, L. Sun, M. Zou et al., "Bioinspired shape-memory graphene film with tunable wettability," Science Advances, vol. 3, no. 6, Article ID e1700004, 2017.

[6] V. V. Tyagi, S. C. Kaushik, S. K. Tyagi, and T. Akiyama, "Development of phase change materials based microencapsulated technology for buildings: a review," Renewable and Sustainable Energy Reviews, vol. 15, no. 2, pp. 1373-1391, 2011.

[7] C. Zhang, Y. Chen, R. Wu, and M. Shi, "Flow boiling in constructal tree-shaped minichannel network," International Journal of Heat and Mass Transfer, vol. 54, no. 1-3, pp. 202-209, 2011.

[8] K. Du, M. Liu, T. Wang et al., "Recent progress in icf target fabrication at RCLF," Matter and Radiation at Extremes, vol. 3, no. 3, pp. 135-144, 2018.

[9] E. M. Campbell, V. N. Goncharov, T. C. Sangster et al., "Laserdirect-drive program: promise, challenge, and path forward," Matter and Radiation at Extremes, vol. 2, no. 2, pp. 37-54, 2017.

[10] K. Lan, J. Liu, Z. Li et al., "Progress in octahedral spherical hohlraum study," Matter and Radiation at Extremes, vol. 1, no. 1, pp. 8-27, 2016.

[11] V. Hessel, H. Löwe, and F. Schönfeld, "Micromixers-a review on passive and active mixing principles," Chemical Engineering Science, vol. 60, no. 8, pp. 2479-2501, 2005. 
[12] F. Sarrazin, L. Prat, N. Di Miceli, G. Cristobal, D. R. Link, and D. A. Weitz, "Mixing characterization inside microdroplets engineered on a microcoalescer," Chemical Engineering Science, vol. 62, no. 4, pp. 1042-1048, 2007.

[13] L. Kong, X. Gao, R. Li, and J. Han, "Bubbles in curved tube flows-an experimental study," International Journal of Heat and Mass Transfer, vol. 105, pp. 180-188, 2017.

[14] X. Liu, Y. Chen, and M. Shi, "Dynamic performance analysis on start-up of closed-loop pulsating heat pipes (clphps)," International Journal of Thermal Sciences, vol. 65, pp. 224233, 2013.

[15] Z. Che, T. N. Wong, and N.-T. Nguyen, "An analytical model for a liquid plug moving in curved microchannels," International Journal of Heat and Mass Transfer, vol. 53, no. 910, pp. 1977-1985, 2010.

[16] Z. Che, N.-T. Nguyen, and T. N. Wong, "Analysis of chaotic mixing in plugs moving in meandering microchannels," Physical Review E, vol. 84, no. 6, Article ID 066309, 2011.

[17] W. A. H. S. S. Wewala, J. K. Kasi, A. K. Kasi, and N. Afzulpurkar, "Design, simulation and comparison of ascending and descending curvilinear microchannels for cancer cell separation from blood," Biomedical Engineering: Applications, Basis and Communications, vol. 25, no. 3, Article ID 1350037, 2013.

[18] J. Wang, J. Wang, L. Feng, and T. Lin, "Fluid mixing in droplet-based microfluidics with a serpentine microchannel," RSC Advances, vol. 5, no. 126, pp. 104138-104144, 2015.

[19] L. Jiang, Y. Zeng, H. Zhou, J. Y. Qu, and S. Yao, "Visualizing millisecond chaotic mixing dynamics in microdroplets: a direct comparison of experiment and simulation," Biomicrofluidics, vol. 6, no. 1, Article ID 012810, 2012.

[20] Z. Y. Luo and B. F. Bai, "Dynamics of capsules enclosing viscoelastic fluid in simple shear flow," Journal of Fluid Mechanics, vol. 840, pp. 656-687, 2018.

[21] Y. Chen, X. Liu, and M. Shi, "Hydrodynamics of double emulsion droplet in shear flow," Applied Physics Letters, vol. 102, no. 5, Article ID 051609, 2013.

[22] Y. Chen, X. Liu, C. Zhang, and Y. Zhao, "Enhancing and suppressing effects of an inner droplet on deformation of a double emulsion droplet under shear," Lab on a Chip, vol. 15, no. 5, pp. 1255-1261, 2015.

[23] C. W. Hirt and B. D. Nichols, "Volume of fluid (VOF) method for the dynamics of free boundaries," Journal of Computational Physics, vol. 39, no. 1, pp. 201-225, 1981.

[24] C. W. Hirt, J. E. Richardson, and K. S. Chen, "Simulation of transient and three-dimensional coating flows using a volume-of-fluid technique," in Proceedings of the 50th Annual Conference of the Society for Imaging and Science Technology, Springfield: Society for Imaging Science and Technology, Boston, MA, USA, May 1997.

[25] J. Li, Y. Y. Renardy, and M. Renardy, "Numerical simulation of breakup of a viscous drop in simple shear flow through a volume-of-fluid method," Physics of Fluids, vol. 12, no. 2, pp. 269-282, 2000.

[26] J. U. Brackbill, D. B. Kothe, and C. Zemach, "A continuum method for modeling surface tension," Journal of Computational Physics, vol. 100, no. 2, pp. 335-354, 1992.

[27] Y. Chen, C. Zhang, M. Shi, and Y. Yang, "Thermal and hydrodynamic characteristics of constructal tree-shaped minichannel heat sink," AIChE Journal, vol. 56, no. 8, pp. 2018-2029, 2010.

[28] K. Yokoi, "A density-scaled continuum surface force model within a balanced force formulation," Journal of Computational Physics, vol. 278, pp. 221-228, 2014.
[29] D. Gueyffier, J. Li, A. Nadim, R. Scardovelli, and S. Zaleski, "Volume-of-fluid interface tracking with smoothed surface stress methods for three-dimensional flows," Journal of Computational Physics, vol. 152, no. 2, pp. 423-456, 1999. 

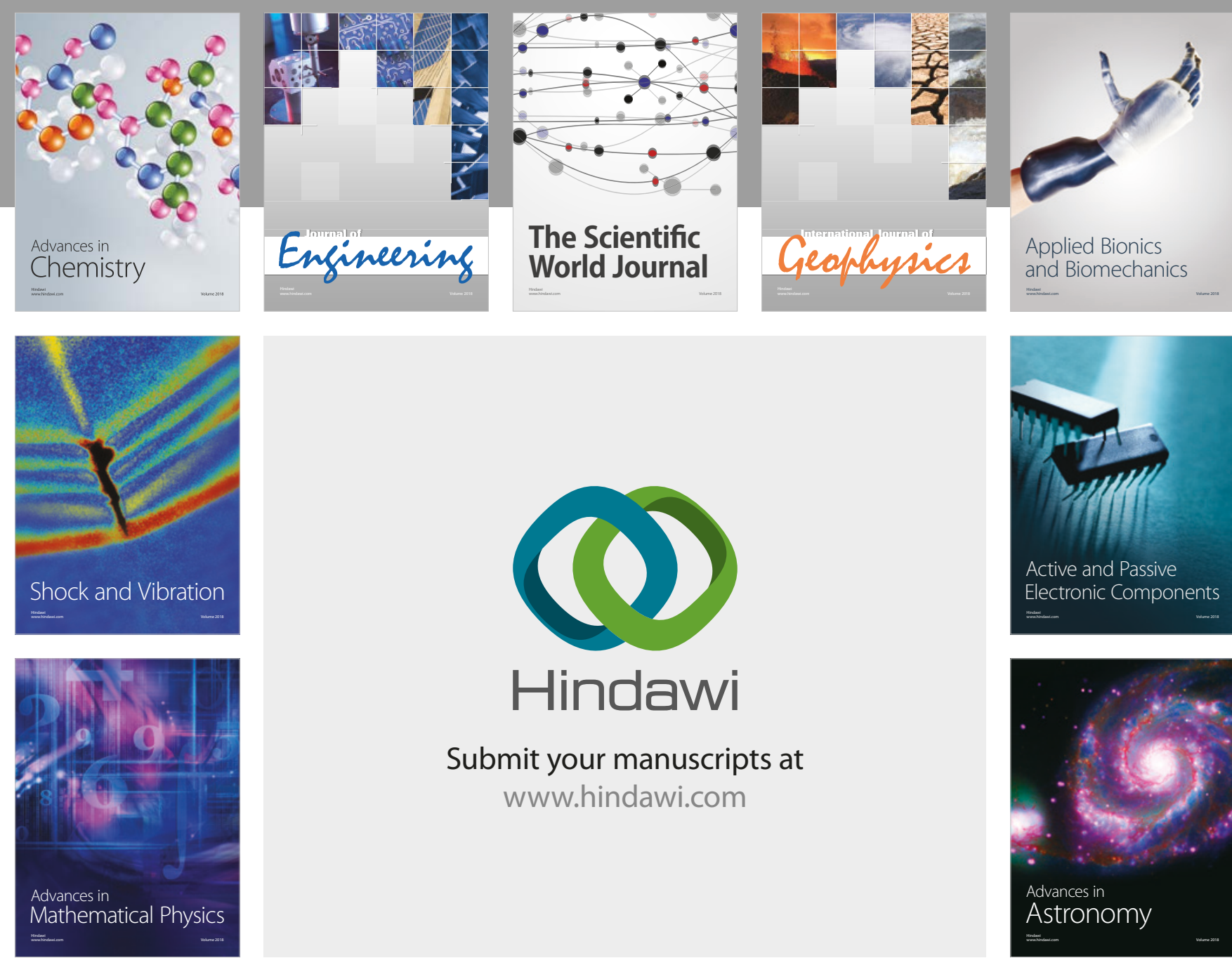

Submit your manuscripts at

www.hindawi.com

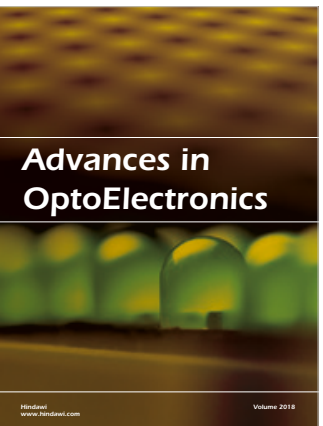

\section{Rotcting Machinery}
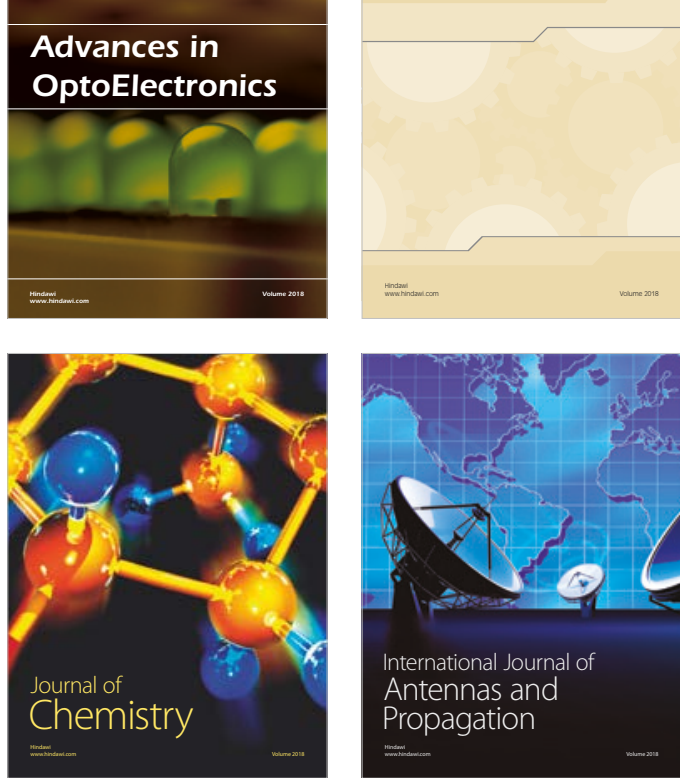

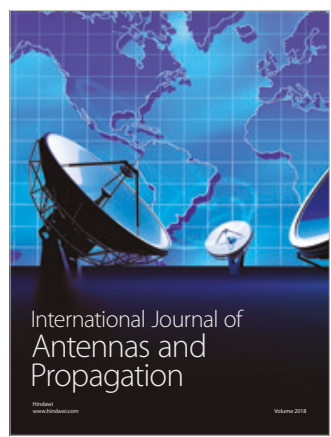

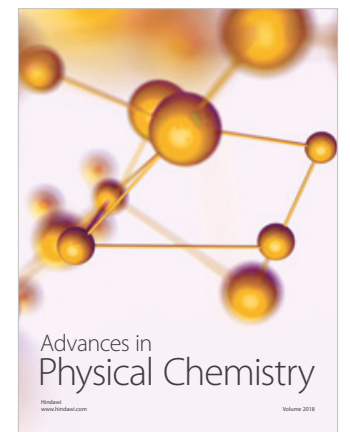

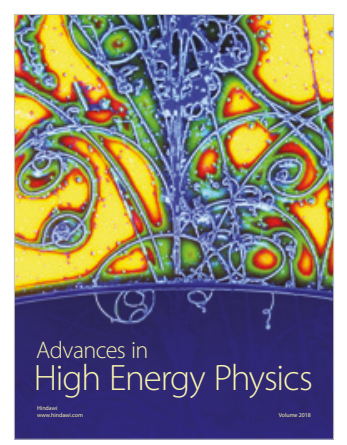

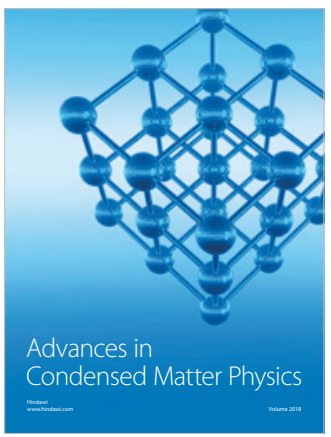

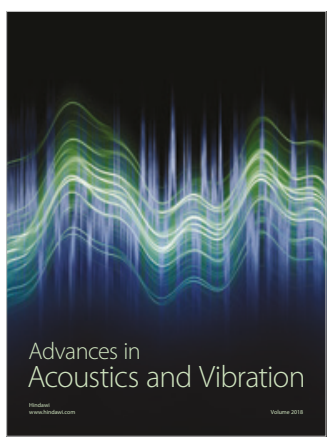

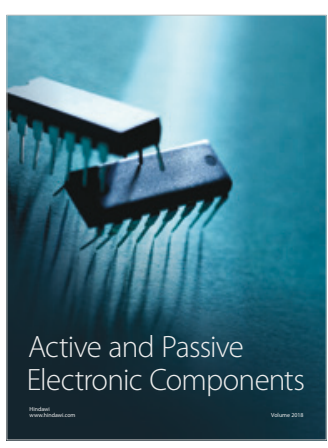
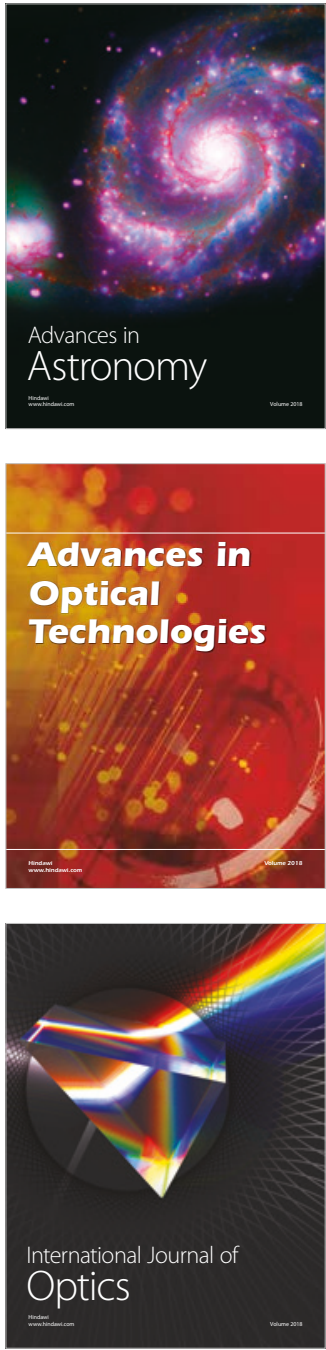